\title{
Soul-Searching at Standing Rock
}

\author{
Jonathan Vaughn
}

\begin{abstract}
This paper proposes the existence of two cultural complexes-a Native Complex and a Pilgrim Complex-active in the United States today. Continuously functioning since the nation's founding, these complexes recently manifested in the \#NoDAPL actions at the Standing Rock reservation and can be seen constellating with and in opposition to each other.
\end{abstract}

Keywords: Standing Rock, \#NoDAPL, cultural complex, colonialism

Singer and Kimbles (2004) have defined cultural complexes as "an inner sociology" and "a description of groups and classes of people as filtered through the psyches of generations of ancestors" (pp. 4-5). The intergenerational aspect of cultural complexes suggests that they bind us to our forebears and to the lands from which they came and went. Within the United States, two cultural complexes that I have named the "Native Complex" and the "Pilgrim Complex" can be traced to the earliest colonial settlement in New England. They seem to have been continuously active for four hundred years, since at least 1620. Moreover, they share unique qualities and characteristics that bind them closely together. The Native Complex is characterized by the perceived invisibility of indigenous peoples - the combined result of both a forced disappearing imposed by colonizers and a choice by the indigenous to disappear, to become invisible, in order to survive. This complex manifested in the 2016 protests by over 300 Native American tribes at the Standing Rock reservation in North Dakota. The Pilgrim Complex, which opposes the Native Complex, is characterized by a separatist drive that demands freedom at all costs (even death) and justifies destructive, genocidal behavior as a means of preserving colonial culture and community. Both complexes intersect at a place where each group intensely seeks freedom, relevance, and acceptance. By reflecting on these two cultural complexes, a collective remembering process may heal collective wounds and bring about what Kimbles (2000) called "an antidote to cultural invisibility" - a way to find soul in the most intractable places, even in the conflict that unfolded at Standing Rock (p. 165).

\section{The Complexes Today: \#NoDAPL}

On one side of the Standing Rock conflict were self-described "water protectors"-American Indian tribal members and elders from over 300 tribes-who were encamped to protest and block drilling of the Dakota Access Pipeline (DAPL). On the other side were the private pipeline company (Energy Transfer Partners), their investors, pipeline workers, law enforcement, and the U.S. government (Whittle, 2016; Yardley, 2016).

The 1,172-mile pipeline, or DAPL for short, is a 30-inch diameter steel pipe built across four states to deliver crude oil from the Bakken shale reserves in North Dakota, across South Dakota and Iowa, to a transfer terminal in Illinois (Aisch \& Lai, 2016; 
Sullivan, 2016). Though largely built on private land and via state powers of eminent domain, the pipeline required permission from the U.S. Army Corps of Engineers (the "Corps") to cross hundreds of waterways in its path, 22 of which had to be built under bodies of water like Lake Oahe, "a dammed section of the federally regulated Missouri River that provides water for the Standing Rock Sioux" (Aisch \& Lai, 2016; Yardley, 2016).

The tribal protests at Standing Rock operated under the Twitter-age banner \#NoDAPL, as well as the phrase Mni Wiconi, Lakota for "water is life" (Crazy Bull, 2016). The Standing Rock Sioux and their supporters, including other private landowners and citizens nationwide, were angry that a pipeline was being built without their consent (as if they were invisible and irrelevant) across sources of drinking water and in close proximity to sacred burial grounds. Their anger was amplified by the blunt manner in which this massive project unfolded in a swift, 18-month process governed by the Corps' euphemistically-titled "Nationwide Permit 12" — which authorized such activities as long as they did "not result in the loss of greater than $1 / 2$-acre of waters of the United States for each single and complete project" (Yardley, 2016). Thus, a new and vital question emerged: "how, they ask, could the Corps view a pipeline's every impact as a 'single and complete project' if it's only being examined piece by piece" (Yardley, 2016).

Furthermore, in protesting, the water protectors were met with violence on an organized, militarized scale not seen in this country in nearly 50 years. On November 20, 2016, just four nights before Thanksgiving, "police used fire hoses to douse protesters in subfreezing temperatures, sending several to the hospital" (Sullivan, 2016). Surface-toair missile-launchers were deployed by the North Dakota Army National Guard to the site as late as January 2017 (Axe, 2017). And while a reprieve in the last days of the Obama administration seemed to slow, if not jeopardize, the progress of the pipeline, the Water Protectors' success was impeded entirely by executive order on the fifth day of the Trump presidency (Baker \& Davenport, 2017).

\section{A Note on Personal Transference}

Since depth psychological inquiry invites authors to consider their personal transference to the topic, it is relevant to note that I come from a long line of American ancestors that goes back fourteen generations. On my paternal grandfather's side my twelfth great-grandparents, John Alden and Priscilla Mullins, were on the Mayflower and settled the Plymouth colony in what would become Massachusetts. In fact, I am descended from four of the families that formed that community in exile-the Alden, Bradford, Mullins, and Rogers families. One of those Plymouth ancestors - all of whom were saved by the hospitality and care of the Wampanoag tribe native to the region-was Elizabeth Alden Pabodie, who was said to be the first colonial child born in New England (Hagan, 2008, p. 2). Since my ancestors were among the first non-native peoples to populate this land, a Pilgrim Complex is sure to be deeply rooted in me. In naming both of these complexes, noting the good and the bad, I honor the collective memory of my ancestors as well as the peoples who lived here long before them. And in naming and remembering perhaps healing can begin in me and in the culture at large. 


\section{Jungian Complex Theory}

Jung (1960/2014b) discovered feeling-toned complexes in his word-association tests while at the Burghölzli hospital in Zurich in the early 1900s (p. 93). Disagreeing with his mentor, Jung declared "the via regia to the unconscious" was not the dream, as Freud had declared, "but the complex, which is the architect of dreams and of symptoms" (p. 101). He also noted that this royal road was not so royal after all. Complexes were "more like a rough and uncommonly devious footpath that often loses itself in the undergrowth and generally leads not into the heart of the unconscious but past it" ( $p$. 101).

Jacobi (1959) went on to outline the nature of complexes in more detail. She said that per 'Jung's definition every complex consists primarily of a 'nuclear element,' a vehicle of meaning, which is beyond the realm of conscious will, unconscious and uncontrollable" and that associations emerge that link them to the nuclear element or core (p. 8). These associations come from both "innate personal disposition" and "individual experiences conditioned by the environment" (p. 9). While Shalit (2002) wrote that "complexes develop around an archetypal core" (p. 14), Samuels (1985) stated that these cores are comprised of an emotion-perceiving experience and not a prescribed list of qualities or symbolic images (p. 53). Jung (1931/1968a) described archetypes at their simplest as "primordial types" or "universal images" (pp. 4-5). Thus, at their cores, complexes must have some primordial, universal "emotional experience of perception," as Samuels (1985) put it directly (p. 53).

Jung's (1960/2014b) extensive research demonstrated that complexes "can have us" or possess us, in a more visceral way of thinking of them (p. 96). In fact, they are "autonomous" and behave like "an animated foreign body in the sphere of consciousness," but they are also "among the normal phenomena of life" (pp. 96, 104). Complexes "lurk as it were in the background of the unconscious" (Jacobi, 1959, p. 10) and act as unconscious contrarians - contrarian, at least from an ego perspective. "Once constellated and actualized, the complex can openly resist the intentions of the ego consciousness, shatter its unity, split off from it" (p. 9). But since complexes are not truly separate or apart from us, they are simply unknown, not negative. In being made known, they emerge from the unconscious shadows. Bringing complexes to consciousness gives them "a better chance of being 'understood' and corrected" as well as "transformed," particularly in the consciousness-making container of the analytic space (p. 11). The key to transformation is the ego. "It is solely the state of the conscious mind, the greater or lesser stability of the ego personality, that determines the role of the complex" (p. 27). How the ego responds determines "whether the conscious mind is capable of understanding, assimilating, and integrating the complex" (p. 27).

Jacobi (1959) asserted that collective complexes pose a greater threat than merely personal ones: "the danger and the corresponding anxiety are greatest when the confrontation is with complexes of the collective unconscious, whose 'explosive charge' can act as an earthquake shattering everything around it" (p. 29). A group carries greater psychic energy — and potentially a greater and more damaging charge - than the energy generated by a single individual's complex. If not brought into consciousness and holistically addressed, such a complex has the potential to wreak widespread distress or devastation. It is this danger, this risk, this potential transformation that is addressed 
below, with the overlay of the collective actions of the \#NoDAPL movement added onto a cultural complex infrastructure.

\section{Cultural Complexes}

If the individual and the collective exist in psyche, in both conscious and unconscious aspects, then various levels between the individual and the collective must give complexes spaces to form, including at the cultural level. A short summary here of where culture and psyche have intersected in Jungian psychology is worthwhile. Building upon Jung's own amorphous writings about the existence of a cultural level — what he called a "sea of historical associations" (Jung, 1936/1968b, p. 86)—Henderson (1990) recognized a "cultural unconscious," in a paper originally presented in 1987. In that paper he referred to his evolving idea as "an area of historical memory that lies between the collective unconscious and the manifest pattern of the culture" (p. 10). Later, Samuels (1985) wrote that complexes were "Jung's way of linking the personal and the collective" (p. 47). He stated that complexes result "from the blend of archetypal core and human experience" and also can directly influence memory (pp. 47-48). If complexes are both the combination of archetypal cores and human experience then what of cultural complexes in the experience of people who live and die together? What of those cultural spaces in the autonomous life of complexes?

Singer and Kimbles (2004) notably brought all of this foundational thought into a single volume in their book, The Cultural Complex. Kimbles (2000) had earlier stated that complexes can be found in "the group's expectations, its definition of itself, its destiny," and that we can find cultural complexes at work "in and through the group's fears, enemies and its attitudes toward other groups" (p. 159). Fortunes, fates, faiths, and fears all serve as a sort of collective mirror held up to the group, giving ghostly form to the complexes present. By looking at the cultural life of the collective-its energies, its language, expression, movements, activities, and values - we begin to see into what lies underneath the surface, what lies just past the respectful veneer of attitudes and behaviors that hold societies together.

Looking into the mirror of Western culture broadly, Bernstein (2005) wrote that "as western European man became increasingly separated from his own tribal roots . . . that same rational function took over the process of separating him increasingly from the transrational dimension, becoming an end unto itself' (p. 34). For Western culture, anything that was not rational, including nature, became identified with the irrational and supernatural (or "transrational"): nature itself became the enemy of Western culture and progress (p. 35). Subsequently, Bernstein diagnosed a "fragmentation complex" at the root of the Western European psyche (p. 36). This reality, the very being of such a complex, "is perceived and experienced as a threat to ego survival - a threat to the very survival of the individual . . . a feeling that can leave one in abject terror" (p. 36). And therein are the behaviors of the Western complex: fear, fragmentation, a pervading feeling of dread and horror, shock and awe. If this complex existed in Western culture broadly speaking, then at a certain point it would be related to and would contain each particular American cultural complex. The American parts would be contained within the Western whole, and this theoretical place is where we locate at least one of the particular 
complexes explored herein, the Pilgrim complex-one layer above the Western fragmentation complex and one layer closer to the individual.

In order to examine the Native and Pilgrim complexes evident in the conflict at Standing Rock, it is important to contextualize the place of the individual within the whole. Kimbles (2000) explained:

Our individual psyches emerge out of the deeper levels of the unconscious and are derived from the collective, communal, and social experiences of humankind. These collective experiences provide at least part of the containers and forms of our individual psychological experiences. They extend backwards into archaic history and forwards into the unknown. None of us are free to step completely outside this river of collective experience. (p. 162)

With respect to psyche, there are no individuals without the influence of the collective, and no collective or cultural level without the actions and reactions of individuals, whether in isolation or in solidarity.

\section{The Two Complexes-Pilgrim and Native}

On one side of the events playing out at Standing Rock are peoples, attitudes, and behaviors that mirror complex reactions seen since the first arrival of colonists some 400 years ago. In particular-if we look at the founding of Plymouth, Massachusetts, and the arrival of the Mayflower, the famous ship filled with devout, anti-establishment Protestants-we see the beginnings of this cultural complex, the Pilgrim Complex. The Pilgrims sought to establish their own religious practices free from the interference by or the authority of the state. They fled to the shores of the New World as a risky, final attempt to be free. This was their Pilgrim Complex in action, one that we can see reflected, strengthened, and amplified today. The complex demands freedom at all costs, even separation and death. Yet while demanding individuality and freedom from the group, they justified the eradication of groups of Native peoples who stood in their way. This Pilgrim Complex could equally be referred to as the Separatist Complex: The Pilgrims left England as dissenters who wanted to separate themselves from the Church of England.

The Pilgrim Complex speaks to what has been happening since the Pilgrims settled on Wampanoag tribal lands. It was as if they said: Pretend the Wampanoag do not exist, indoctrinate them, take them in, assimilate them, but do not let them be seen or heard or left to their own devices. If we cannot push them far enough away, if we cannot get rid of them entirely, despite all trying, then let us hide them away, in remote corners. This ideology was enshrined in Massachusetts colonial law in 1675, which allowed for anyone "that shall finde any Indian travelling or skulking in any of our Towns or Woods... to command them under their Guard and Examination, or to kill them and destroy them as they best may or can" (Lepore, 1998, p. 183). The fragmented-those lonely, forgotten, disconnected, separated-were now doing the fragmenting. Those seeking the right to be separate were now demanding that everyone in their reach be the same, identical, homogeneous. The Pilgrim complex is one of hiding, shadows, obscurity, and of broken promises. 
On the other side stand Native Americans, those indigenous to the American continent. Their complex emerges in direct reaction to the destructive, genocidal behavior of the Pilgrims and other colonists. This Native Complex, which started as defense against genocide, may have protected Native Americans from complete annihilation. And those who did survive seemingly disappeared. At first they were intentionally forced to disappear, murdered outright or pushed off of their homelands. And later some survivors also chose to disappear, to render themselves invisible, to assimilate enough to become unnoticeable, and by doing so to ensure their survival. Here the characteristic invisibility of the Native Complex is evident.

The power and reach of this complex can be seen in the popular book The Last of the Mohicans, written in 1826, as well as the contemporary movie of the same name (Cooper, 1826/2003; Mann, 1992). The sad irony is that there was no last Mohican, no final man, the last of his kind. The Mohicans survive unto today. Cooper's novel was a cultural lie attempting to obscure the truth because reality was too painful to face, too treacherous to admit. Whereas Pilgrims and other colonizers tried to eradicate the indigenous peoples, the Native Americans survived. As Chingachgook, the father of Uncas, the so-called last of the Mohicans, says at the close of the book, "I am a blazed pine, in a clearing of the pale faces" (1826/2003, p. 363). Chingachgook himself survives and stands alone, "a blazed pine," despite every violent and destructive act by the palefaced colonists. Even amidst perceived isolation and destruction a tree still grows and thrives. This stark reality counters the malevolent myth that whole tribes of Native peoples simply vanished. They survived despite every attempt to make them disappear, despite every effort to destroy them.

Of course, this complex has been deeply destructive too. Building on the tale above, Native Americans have been forgotten at each step of the American story. The fragmentation and marginalization that began with the Pilgrims have left them at the margins of society and the edge of prosperity. While the young nation of colonists (not just English Pilgrims, but English Anglicans and Catholics, as well as Dutch, German, French, and others) moved on, Native Americans were often left in poverty and despair. Ultimately the desperate and necessary choice to blend in came with a heavy price- the burden of invisibility.

The defensive shell of this complex manifests in modern Native Americans as separateness, as desperate escapism by the young, as awful cycles of poverty and substance abuse that mask the root problems. This defensive, complex behavior was reflected in the words of one Water Protector at Standing Rock: "Back home, it's drugs, alcohol, no jobs. People don't really know how to survive. It's hopeless. All we have left is the river" (Wong, 2016).

The theory of historical trauma- "a legacy of chronic trauma and unresolved grief across generations" - explains these cyclical, defensive behaviors that vex Native communities (Brave Heart \& DeBruyn, 1998, p. 60). The trauma of the violence against the Native Americans is what seems to be most invisible, and herein lies the reason this complex keeps feeding and growing. The violence began early. Lands were often acquired through seizure, treachery, or violence. And no matter how the land was acquired, property was often so cherished by the colonists that they put their own families in harm's way in extreme efforts to preserve prized property. As Lepore (1998) noted, 
"this kind of attachment was not at all uncommon," as was the case with the colonist Thomas Wakely and his family in 1675 (p. 76). Native blood was spilled over land, over colonial desires for possession and consumption, over an uncontrollable appetite for resources. Loss was constant: loss of family, land, home, familiarity, culture, and even historical evidence of their very existence and survival. This trauma, this loss, did not stop with the first violent strike. The trauma has persisted since Plymouth, continued with the 100-year-old policy of forcing Native American children to attend government boarding schools (which did not end until the 1970s), and it persists in many aspects of Native life today (Fortunate Eagle, 2002, p. 18). The trauma is pervasive even as the violence against them continues to be perpetuated.

What are a people supposed to do when in the grips of such a collective complex? How should they behave? I suggest that the answer is memory. Collective remembering is the path to wholeness.

\section{Analysis: \#NoDAPL and the Complexes in Conflict}

The archetypal cores at the center of each complex-Pilgrim and Native, as they constellate around and in tension with one another-are similar. Each one displays dual aspects: the fear of invisibility combined with the desire for freedom. At that core rests a common need for acceptance as well as a need to define what is sacred and holy. In fact, both groups seem to express universal fears of invisibility, of being without voice or power, alongside an intense need to be free, truly free, whether Native or Pilgrim, Wampanoag or white, Standing Rock Sioux or Bakken pipeworker. Indeed, because their complex behaviors so closely mirror and interact with each other, it may be possible after 14 generations that these two complexes are now fused into a single complex. Yet this possibility would need to be the basis of a broader and deeper study, as noted below.

The Pilgrims themselves feared being rendered powerless by those in power in England. Their separation and isolation was clear when William Bradford wrote, on that first morning in the New World, that "they had now no friends to welcome them nor inns to entertain or fresh their weatherbeaten bodies; no houses or much less towns to repair to, to seek for succor" (as cited in Philbrick, 2006, p. 46). After they were exiled themselves, the exiled - the separated Pilgrims-became the exilers, demanding homogeneity even by means of violence. Native Americans continue to fear their forced invisibility too. LaNada Boyer, a Shoshone-Bannock protestor at the Indian occupation of Alcatraz in 1969, said, "It was like we were an invisible people. They recognized everyone else, but they never recognized the Indian people - it was like we were a part of a museum" (Johnson, 1997, p. 11). While exiled to reservations, Native Americans seek heterogeneity in order to preserve their way of life and accept separation from the whole of the United States so as not to be devoured by it. And the defensive, isolating behaviors that emerge further enrage and re-engage the homogenizing, violent complex opposing them. Thus, the cycle of these entwined complexes starts all over and repeats again and again.

Returning to contemporary events at Standing Rock, the disregard shown to the people (whose land and water was in the path of profit) is evident. Two facts are particularly telling: the seizure of land by invoking eminent domain-200 parcels in Iowa alone (Aisch \& Lai, 2016). And then there is the fact that the legally questionable review 
process by the U.S. Army Corps of Engineers required consideration of the pipeline, as Yardley (2016) noted, to be made "piece by piece" (Yardley, 2016). As he explained:

Rather than broadly examining the impact a major pipeline could have across its length, looking at cumulative effects on water, air quality, land and animal species or the climate-changing emissions a pipeline might enable, the Corps typically assesses big pipelines as a series of much smaller ones, sometimes hundreds of smaller ones-breaking them up into segments to be reviewed at specific water and wetland locations.

In considering these in pieces rather than as a single pipeline the Corps of Engineers was contending with the core of its own Pilgrim complex: the Corps itself was fragmented, as was its process. The individuals involved were caught up in the complex. And in return the Army literally fragmented the review process, against any sane or rational explanation of the total impacts on wildlife, water, or other natural resources. Yes, the process was itself a bureaucratic strategy to complete the project, but it was reflective of deeper, underlying traits and patterns of behavior that are historically familiar. The people of the Corps were so attached to land and property (much of it seized through the power of eminent domain) that they once again revealed the colonial Pilgrim attitude of valuing property over life and free will, especially as it pertained to the Standing Rock Sioux. Thus, the Corps seems to have embodied the hatred of nature endemic in the Western European psyche.

The fact that the breadth of this fragmented process is so obfuscated-by bureaucracy and secrecy-reinforces the power of the Pilgrim Complex at work here, as well as the Western fragmentation that lies, even more powerfully, underneath it. There is no clarity, to date, as to how many pieces resulted when the Corps carved up the 1,172mile pipeline. The level of the fragmentation is undistinguishable, which is a terrifying thought psychologically. How could a project of such scale, one that crosses some 200 waterways, be so diminished, so trivialized as insignificant and even failsafe (Colwell, 2016)? Is extracting such a finite resource so important? What costs are too great to justify the opportunity and the destruction created along the way? Ultimately consideration of the pipeline seems to come down to the independence of a people to decide their own fate and to choose their own destiny, in a system that values fairness and order for all. The goal of this analysis is not to value or devalue the economic worth of the pipeline as a whole. The aim is to bring light to the peoples and the cultures in conflict. At work in this tale are recurring patterns of behavior, seemingly induced by complex dynamics, which have wreaked havoc and violence for centuries. Only if the violent totality of 400 years of history is confronted will healing be possible.

Considering the behavior of the Corps and of the DAPL owners (Energy Transfer Partners) and their disregard for life, safety, and security, the age-old complex pattern can be seen re-emerging. Once again the fragmented are now doing the fragmenting. Like their Pilgrim forebears before them, they are perpetuating a cycle of fragmentation, destruction, and annihilation, and they are further preventing integration and wholeness.

The ramifications in terms of psyche, on the collective level of psyche in particular, seem to be significant. It seems as if assimilation and integration are actively being prevented. The efforts of consciousness, of remembering the long history of colonization, are seemingly being thwarted; instead unconsciousness is being 
encouraged. In short, active repression seems to be at work. And with repression comes the dangerous threat of a violent reaction. Jung (1945/2014a) told us that the more negative the conscious attitude "the more repulsive, aggressive, and frightening is the face which the dissociated content assumes" (p. 342). The implications are frightening: without consciousness-making efforts, efforts to prevent further fragmentation, an even more violent reaction awaits - an enantiodromia, a violent swing in an opposing direction. Would this reaction be one that emerges from Native Americans or from elsewhere within the culture? Would such a reaction emerge from Mother Nature herself, whose resources are being ripped from her without regard to the consequences? Of course, there is no definitive way to know: we only know that to watch such violent fragmentation occur is to encourage psychological disaster at a minimum.

Amidst the millions of people impacted by this pipeline's construction, the Standing Rock Sioux had been ignored and rendered invisible until they bravely demanded to be heard, even in the face of violence. The collective actions of the 300 tribes that stood with the Standing Rock Sioux confronted the invisibility that has plagued all Native Americans for centuries. But even now they risk being relegated to the margins, ignored, and silenced yet again, for the threats are real and sustained.

In January 2017, under executive order, the DAPL construction was expedited and by June of the same year crude oil began to flow (Brown, 2018). Yet in just six months of operation the pipeline leaked five times across four states, and its sister pipeline, the Energy Transfer Crude Oil pipeline, which transfers the oil from the DAPL terminal in Illinois to the Gulf Coast refineries, leaked three times (Brown, 2018). The fears of the Standing Rock Sioux and the additional 300 tribes have already come to pass.

As Chief Arvol Looking Horse (2018), the 19th Keeper of the Sacred Bundle and spiritual leader of the Lakota, Dakota, and Nakota people, has written, "Standing Rock is everywhere .... What happened at Standing Rock has awakened many of my own people, and people across the world."

\section{Concluding Thoughts and Opportunities}

Fortunately, the sheer enormity of cultural complexes illuminates a way for us to contend with them: "they require a collective response" that must include "collective memory" as an "antidote to cultural invisibility": "the good, the bad, and the traumas must be worked with in order to sustain and give grounding to culture and individual identity" (Kimbles, 2000, pp. 163, 165, 167). Active remembrance and speaking the truth are the keys. Greater consciousness is being brought by the Native Americans by their actions at Standing Rock, but greater consciousness is still needed by all, including the descendants of the Pilgrims and the other peoples that colonized this land. Given the state of the world, this battle is likely only the beginning in a long, painful, very disruptive struggle for the future.

Despite the ongoing threats and dangers, hope remains, for awareness and consciousness have emerged. Yet memory alone is ineffectual without action, without substantive changes to the behaviors that have sustained these complexes for centuries. Memory is meaningless in the face of global climate destruction-wrought by the reliance on fossil fuels, as described above - unless such memory is accompanied by actions that will bring peoples and cultures together and will point them collectively 
toward a sustainable future. Here there is hope that the actions at Standing Rock will lead to "ideas on how to move toward sustainable living in our relationship to land, water, and food" (Looking Horse, 2018).

Vocational opportunities for depth psychologists seem numerous. Beyond the ongoing need for clinical, therapeutic work, these two cultural groups need to talk about the emergent issues together. Dream circles and imaginal group work with both Native and non-Native peoples could help bring everyone into the same safe space to encounter the collective unconscious and to tackle the painful, difficult issues described above. Additional opportunities exist at the research level as well: it is entirely possible that the two complexes described here, once separate and distinct, have coexisted for so long that they have become one enmeshed complex, like subatomic particles linked by a common nucleus, by a complex archetypal core - one that equally fears invisibility and yearns for freedom. After 400 years and 14 generations, perhaps they are now so co-dependent, so fundamental to the other, that they should be considered as one cultural complex. The implications of such a phenomenon could be enormous and should be explored further.

Ultimately much more can and should be written about the full truth of our nation's founding and the violence it imposed on Native peoples. Educational efforts are critical because all sides of the story must be heard, the good along with the bad, the frightening, and the awful. Education is fundamental to memory and to the process of remembering. History is particularly significant in these educational efforts, while the studies of literature, art, politics, law, and other disciplines are helpful as well. The efficacy of all such educational efforts hinges on presenting and remembering all aspects of our past, not just one side's viewpoints or opinions - not just the colonizers' storiesbut the unvarnished perspectives of every possible side. The truth needs to be spoken and heard, for the violence did not end centuries ago: Standing Rock is proof that the suffering continues to be sustained here and now.

Because the Pilgrim Complex is deeply rooted in me, I have my own work to continue, my own questions to ask: What do I fail to see or know about the power and effects of this complex? Does it so possess me that I am still unable to see the damage of my actions or of my own ancestors? What am I unable to see or know of the Native American experience or of the Native complex? All of these questions linger. When I allow these questions to remain - to pervade my views of our country, our culture, and our world - surely I am starting to make room for consciousness. Hopefully this constant questioning creates space for the transcendent function to work, to facilitate in me what von Franz (1978/1995) said was "a transition from one attitude to another" (p. 83). Yet I do not exist alone in a cultural complex, and I must engage with others in my culture and in other cultures to ensure that any destructive effects are disempowered and mitigated.

Ultimately complexes are powerful, autonomous aspects of psyche that live not only in individuals but also in groups. To allow them to be integrated successfully, consciously - to give them space to cohabitate with ego and all the other host of complexes that live in us as individuals and as a collective-requires that we honor them publicly, as a group, and memorialize how we came to embody them, for better and for worse. This difficult collective act requires bringing the truth out into the light of day and speaking it with honor, dignity, and respect for all who have come before us, Native and non-Native alike. Only then do we have any hope of saving this place we collectively call 
home, not only Turtle Island - the Native name for North America-but for all of Unci Maka, the Lakota name for Grandmother Earth (Crazy Bull, 2016).

\section{Contributor}

Jonathan Vaughn (MA, MPA) is a PhD student in Depth Psychology, Jungian and Archetypal Studies at Pacifica Graduate Institute. He is a writer and filmmaker, as well as an experienced university and arts administrator. His research focuses on the psychology of place, particularly in the age of climate change.

\section{References}

Aisch, G., \& Lai, K. K. R. (2016, November 23). The conflicts along 1,172 miles of the Dakota Access Pipeline. The New York Times. Retrieved from http://www.nytimes.com

Axe, D. (2017, January 17). National Guard deploys missile launchers to Dakota Access Pipeline to 'observe' protestors. The Daily Beast. Retrieved from http://www.thedailybeast.com

Baker, P., \& Davenport, C. (2017, January 24). Trump revives Keystone Pipeline rejected by Obama. The New York Times. Retrieved from https://www.nytimes.com

Bernstein, J. (2005). Living in the borderland. New York, NY: Routledge.

Brave Heart, M. Y. H., \& DeBruyn, L. M. (1998). The American Indian holocaust: Healing historical unresolved grief. American Indian and Alaska Native Mental Health Research, 8(2), 60-82.

Brown, A. (2018, January 9). Five spills, six months in operation: Dakota Access track record highlights unavoidable reality - pipelines leak. The Intercept. Retrieved from https://www.theintercept.com

Colwell, C. (2016, November 22). Destroying heritage: How the Dakota Access Pipeline plans went all wrong. Salon. Retrieved from http://www.salon.com

Cooper, J. F. (2003). The last of the Mohicans. New York, NY: Barnes and Noble Classics. (Original work published 1826)

Crazy Bull, C. (2016, September 22). Woonspe-education gives meaning to Mni Wiconi-water is life. Indian Country Media Network. Retrieved from https://indiancountrymedianetwork.com

Fortunate Eagle, A. (2002). Heart of the rock: The Indian invasion of Alcatraz. Norman, OK: University of Oklahoma Press.

Franz, M.-L. von (1995). Projection and re-collection in Jungian psychology. (W. Kennedy, Trans.). Chicago, IL: Open Court. (Original work published 1978)

Hagan, S. (2008). Elizabeth Alden Pabodie, c. 1623-1717: Pilgrim daughter of Little Compton. In Portraits in time: Three centuries of remarkable residents, 1600 1900. Little Compton, RI: The Little Compton Historical Society.

Henderson, J. L. (1990). The cultural unconscious. In Shadow and self: Selected papers in analytical psychology (pp. 103-113). Wilmette, IL: Chiron.

Jacobi, J. (1959). Complex / archetype / symbol in the psychology of C. G. Jung. Princeton, NJ: Princeton University Press. 
Johnson, T. R. (1997). We hold the rock: The Indian occupation of Alcatraz, 1969 to 1971. San Francisco, CA: Golden Gate National Parks Conservancy.

Jung, C. G. (1968a). Archetypes of the collective unconscious (R. F. C. Hull, Trans.). In H. Read et al (Series Eds.), The collected works of C. G. Jung (Vol. 9, part i, 2nd ed., pp. 4-41). Princeton, NJ: Princeton University Press. (Original work published 1931)

Jung, C. G. (1968b). Individual dream symbolism in relation to alchemy (R. F. C. Hull, Trans.). In H. Read et al. (Series Eds.), The collected works of C. G. Jung (Vol. 12, 2nd ed., pp. 39-224). Princeton, NJ: Princeton University Press. (Original work published 1936)

Jung, C. G. (2014a). The philosophical tree (R. F. C. Hull, Trans.). In H. Read et al. (Series Eds.), The collected works of C. G. Jung: Complete digital edition (Vol. 13, pp. 251-349). Retrieved from http://www.ebscohost.com. (Original work published in 1945).

Jung, C. G. (2014b). A review of the complex theory (R. F. C. Hull, Trans.). In H. Read et al. (Series Eds.), The collected works of C. G. Jung: Complete digital edition (Vol. 8, pp. 92-104). Retrieved from http://www.ebscohost.com. (Original work published in 1960).

Kimbles, S. (2000). The cultural complex and the myth of invisibility. In T. Singer (Ed.), The vision thing: Myth, politics and psyche in the world (pp. 155-169). London, UK: Routledge.

Lepore, J. (1998). The name of war: King Philip's war and the origins of American identity. New York, NY: Vintage.

Looking Horse, C. A. (2018, February 22). Standing Rock is everywhere: One year later. The Guardian. Retrieved from https://www.theguardian.com

Mann, M. (Director), \& Lowry, H. \& Mann, M. (Producers). (1992). The last of the Mohicans. [Motion Picture]. United States: 20th Century Fox.

Philbrick, N. (2006). Mayflower. New York, NY: Penguin Books.

Samuels, A. (1985). Jung and the post-Jungians. London, UK: Tavistock/Routledge.

Shalit, E. (2002). The complex: Path of transformation from archetype to ego. Toronto, Canada: Inner City Books.

Singer, T., \& Kimbles, S. (Eds.) (2004). The cultural complex: Contemporary Jungian perspectives on psyche and society. Hove, UK: Brunner-Routledge.

Sullivan, K. (2016, December 2). “This pipeline represents something deeper”: Voices from Standing Rock. The Washington Post. Retrieved from https://www.washingtonpost.com

Whittle, J. (2016, November 30). "We opened eyes": at Standing Rock, my fellow Native Americans make history. The Guardian. Retrieved from https://www.theguardian.com

Wong, J. C. (2016, December 8). "This is an awakening": Native Americans find new hope after Standing Rock. The Guardian. Retrieved from https://www.theguardian.com 
Yardley, W. (2016, November 9). There's a reason few even knew the Dakota Access pipeline was being built. Los Angeles Times. Retrieved from http://www.latimes.com 